\title{
The clinical and laboratory correlates of an increased urinary 5-hydroxyindoleacetic acid
}

\author{
WP Tormey, RJ FitzGerald
}

\begin{abstract}
Summary
Over a five-and-a-half-year period, there were 298 laboratory requests for urinary 5-hydroxyindoleacetic acid (5-HIAA). The clinical and laboratory associations of the 24 patients in which there were 43 urinary 5-HIAA $24-h$ collection results greater than the laboratory upper reference limit are detailed. Four were confirmed carcinoid tumours and two were phaeochromocytomas. Flushing was a prominent symptom in $46 \%$ and diarrhoea or altered bowel habit in $37 \%$. Associated with the raised urinary 5HIAA values were increased levels of 4hydroxy-3-methoxymandelic acid and homovanillic acid in $14.3 \%$ and $21 \%$, respectively, of those collections where the metabolites were requested. Diagnostic imaging was performed in $57 \%$. While the specificity was $88 \%$, 5-HIAA is relatively insensitive in the diagnosis of carcinoid tumours and a more widespread use of diagnostic imaging including isotope scanning with labelled metaiodo-benzylguanidine, vasoactive intestinal peptide and octreotide is suggested.
\end{abstract}

Keywords: hydroxyindoleacetic acid analysis, audit

Carcinoid tumours are usually linked to the chemical pathology laboratory through the measurement of urinary 5-hydroxyindoleacetic acid (5-HIAA). Carcinoid tumours derive from enterochromaffin cells which are found in the gastrointestinal system including the salivary glands, pancreas and biliary tree, and in the bronchial tree, thyroid, ovary, thymus or uterus and have a reported frequency of about 3.2 to 15 cases per million population per year. ${ }^{1-3}$ They may be found incidentally in $0.50 \%$ to $0.75 \%$ of autopsies. ${ }^{4}$ Despite an expected annual incidence of 20 new cases per year, a 15-year study in Northern Ireland reported an annual incidence of 13 per million of the population for carcinoid tumour and no patient presented with the carcinoid syndrome. ${ }^{1}$ They are slow growing and the average time lapse between symptoms and diagnosis is 4.5 years. 5 -Hydroxytryptamine $(5-\mathrm{HT})$ production by these tumours depends on the site of origin. Ileal and other mid-gut carcinoids secrete large quantities of 5-HT which are then metabolised to 5-HIAA and excreted in the urine. Fore-gut tumours such as bronchial, pancreatic, duodenal or biliary carcinoids secrete mainly 5-hydroxytryptophan (5-HTP) which is metabolised to 5-HT and 5-HIAA at other sites. In carcinoids that present with carcinoid syndrome, liver metastases are present in about $95 \%$ except where the primary site is in the lungs or ovaries. Carcinoids may produce histamine, bradykinin, prostaglandins, enkephalins and endorphins, gastrin, motilin, neurotensin, arginine vasopressin, chorionic gonadotropin, insulin, adrenocorticotrophic hormone and catecholamines. ${ }^{2}$

Traditionally, the reason for a laboratory request for urinary 5-HIAA is to confirm the presence of a carcinoid tumour. We review the clinical and laboratory associations of the 24 cases from Beaumont and James Connolly Memorial Hospitals where at least one 24-h urinary collection for 5-HIAA was greater than the reference range during the five-and-a-half years from 1989 and the problems of a false positive urinary 5-HIAA are discussed.

\section{Methods}

The case records for each patient were studied to establish the principle symptoms resulting in the laboratory request for urinary 5-HIAA. There were 13 women and 11 men, all inpatients, ranging from 15 to 84 years with a median age of 57 years. The ward drug dispensing record was inspected to establish which drugs were dispensed to the patients by the nursing staff during the course of the 24-h collection. The urine collections were considered complete when the volume was greater than $500 \mathrm{ml}$. It proved impossible to establish retrospectively whether the patients had consumed bananas, pineapples or other fruits which may cause minor elevations in urinary 5-HIAA excretion. 5-HIAA was measured by high performance liquid chromatography (HPLC) with electrochemical detection after the method of Davidson, and the reference range was $8-47 \mu \mathrm{mol} / 24 \mathrm{~h} .{ }^{5}$ The betweenbatch coefficient of variation $(n=20)$ for 5 HIAA in this laboratory was $15.3 \%$ at $25 \mu \mathrm{mol} /$ 1 and $6.4 \%$ at $155 \mu \mathrm{mol} / 1$. Drug interferences may arise. The application of a detector voltage of +0.67 volts was used as neither atenolol nor paracetamol interfere with the assay at this detector voltage.

\section{Results}

There were 43 abnormal 5-HIAA results from 24 patients within the total 298 tests carried out 
in the 5.5-year period, which represents $14.4 \%$ of the total. The clinical diagnoses are shown in the table. Flushing was a prominent symptom in $11(46 \%)$ and diarrhoea or altered bowel habit was present in nine $(37 \%)$. Computed tomography (CT) scans were performed on nine patients and abdominal ultrasound examinations on a further three. Thus $57 \%$ of these patients underwent diagnostic imaging. One meta-iodobenzylguanidine (MIBG) scan was performed where a CT scan was negative and was found to be normal. Other than two phaeochromocytomas, the abdominal CT scans were negative and were unnecessary for diagnosis of the three carcinoids. Thus there was an underutilisation of the available diagnostic imaging facilities for adequate patient follow-up. Where sensitivity is positivity in disease and specificity is the absence of a particular disease, calculation of these indicators for 5-HIAA in carcinoid tumours is at best an approximation. The specificity is $88 \%$ assuming that all the negatives are true and that all the non-histologically proven

Table The clinical correlations of the raised 5-HIAA values. Preand post-op indicate the timing of the urine collection relative to surgery

\begin{tabular}{|c|c|}
\hline Case and diagnosis & $\begin{array}{l}\text { 5-HIAA level } \\
(\mu \mathrm{mol} / 24 \mathrm{~h})\end{array}$ \\
\hline 1 carcinoid tumour & $\begin{array}{r}608 \text { (pre-op) } \\
79 \text { (post-op) } \\
78 \text { (post-op) } \\
63 \text { (post-op) }\end{array}$ \\
\hline 2 carcinoid tumour & 822 (post-op) \\
\hline 3 carcinoid tumour & 1121 (post- \\
\hline 4 carcinoid tumour & $\begin{array}{l}234 \\
324\end{array}$ \\
\hline 5 phaeochromocytoma & 85 (post-op) \\
\hline 6 phaeochromocytoma & 73 (pre-op) \\
\hline 7 gut hormone secreting tumour & 58 \\
\hline 8 possible adrenal mass on ultrasound & 81.6 \\
\hline $\begin{array}{l}9 \text { neurofibromatosis with a possible carcinoid } \\
\text { tumour }\end{array}$ & $\begin{array}{l}53 \\
45.4 \\
176\end{array}$ \\
\hline 10 malignant neuroleptic syndrome & $\begin{array}{l}69 \\
19\end{array}$ \\
\hline 11 Klippel Trenaunay syndrome & 51 \\
\hline 12 hypernephroma - poor anaesthetic risk & $\begin{array}{l}95 \\
79\end{array}$ \\
\hline 13 diabetes mellitus with flushing and hypertension & $\begin{array}{r}84 \\
136 \\
14 \\
31\end{array}$ \\
\hline $\begin{array}{l}14 \text { flushing associated with a calcium channel blocker } \\
15 \text { flushing associated with a calcium channel blocker } \\
16 \text { asthma and theophylline } \\
17 \text { possible carcinoid tumour }\end{array}$ & $\begin{array}{l}60 \\
55.4 \\
56.7 \\
83.2 \\
89.6 \\
84.0\end{array}$ \\
\hline 18 palpitations associated with a patent foramen ovale & $\begin{array}{l}59.4 \\
20.3 \\
11.1 \\
11.6 \\
20.7\end{array}$ \\
\hline 19 palpitations and flushing & 72.2 \\
\hline $\begin{array}{l}20 \text { flushing, sweating with cardiac failure from valvular } \\
\text { heart disease }\end{array}$ & 66.1 \\
\hline 21 flushing & 96.2 \\
\hline 22 flushing & 82.6 \\
\hline $\begin{array}{l}23 \text { episodic diarrhoea with pituitary disease } \\
24 \text { hypertension }\end{array}$ & $\begin{array}{l}85.5 \\
56\end{array}$ \\
\hline
\end{tabular}

positives are truly false. Although we do not know of any false negatives, given the symptomatic silence before metastases, there undoubtedly are a number, making a sensitivity figure of $100 \%$ invalid. However, for the carcinoid syndrome, the sensitivity is $100 \%$ and the specificity is $88 \%$.

4-Hydroxy-3-methoxy-mandelic acid (HMMA) values corresponding to a raised 5-HIAA level were available from the $35 \mathrm{col}$ lections where they had been requested and five $(14.3 \%)$ of these HMMA values were greater than the upper reference limit of $45 \mu \mathrm{mol} / 24 \mathrm{~h}$. Levels of homovanillic acid (HVA) corresponding to an increased 5-HIAA were available from 28 collections and six $(21 \%)$ of these were above the upper reference limit of $40 \mu \mathrm{mol} /$ $24 \mathrm{~h}$.

A brief clinical summary of the patients with raised urinary 5-HIAA is outlined. Three of the four carcinoid tumours were histologically confirmed. Two originated in the ileum, one in the caecum and the primary site was unknown in the fourth. Each had liver metastases. In case 1, there was a raised HMMA of $66 \mu \mathrm{mol} / 1$ and HVA of $48 \mu \mathrm{mol} / 1$ whereas these metabolites were normal in the other three. In two of the carcinoids, the diagnosis was unsuspected and was made histologically postoperatively. All four had carcinoid symptoms on clinical review.

The two phaeochromocytomas were histologically confirmed and the elevated 5HIAAs had corresponding values for free catecholamines, HMMA and HVA which were normal during that particular collection, one of which was pre-operative. One female patient (case 7) with a presumed gut hormone problem, despite batteries of gut hormone analyses at supraregional centres in London, England, and Belfast, Northern Ireland, which had proved negative, complained of watery diarrhoea and a facial rash with flushing. Glucagonoma had been specifically excluded. Episodic severe hypotension compromising her renal function occurred and abdominal ultrasound and CT scans proved normal. An earlier 5-HIAA collection in another hospital had been normal. In case 8, weight loss, diarrhoea, episodic asthma, oesophagitis and hyperreninaemic hypertension were present but CT and MIBG scans and urinary free catecholamines were negative. Lisinopril and ranitidine was the drug therapy and the cause of the elevated 5-HIAA levels of 81.6 remained enigmatic. In case 9 , sweating, flushing and occasional palpitations were present. Telangiectasia were present as was an acoustic neuroma. Drug therapy included diltiazem and the presence of carcinoid tumour remains a possibility. Malignant neuroleptic syndrome was diagnosed in a patient from a psychiatric hospital in whom the urinary HMMA, HVA, noradrenaline, adrenaline and dopamine were all elevated but where the free catecholamines returned to normal and the metabolites to almost normal within days. However, in the absence of diagnostic imaging, the diagnosis appears unsafe. In case 11, a 19-year-old, flushing, sweating, vague abdominal discomfort, telangiectasia and 
varicosities were noted and an abdominal ultrasound examination was normal. Case 12 , an 84-year-old female unfit for surgical operation, had a large hypernephroma, diabetes mellitus and hypertension for which she was taking nifedipine, doxazosin, glibenclamide and cimetidine. Case 13 was taking atenolol and abdominal CT and ultrasound scans were normal. In cases 14 and 15 , nifedipine and verapamil therapy for hypertension were the likely causes and theophylline as part of the bronchodilator treatment in asthma may have been a factor in case 16 . In case 17 , a CT scan and urinary free catecholamines were negative but flushing, palpitations and rash were persistent symptoms and carcinoid remains a possibility. Case 18 had a normal CT scan and the initial value was coincidental. Case 19 was a 39-year-old with flushing, palpitations from atrial fibrillation and obesity. Digoxin was prescribed and carcinoid was considered unlikely. Case 20 was a 54-year-old with cardiac failure from valvular heart disease who had episodes of hypertension, flushing and sweating and an altered bowel habit. The noradrenaline was raised at $1292 \mu \mathrm{mol} / 24 \mathrm{~h}$ (ref $<900$ ) but no abdominal imaging had been performed and therefore phaeochromocytoma has not been ruled out. Paroxysmal flushes and pyelonephritis were the presenting problems in case 21 and a repeat specimen was normal. In case 22 , flushes and abdominal pain in a 15year-old with ureteric re-implants were the problems and abdominal ultrasound, urography and isotope renograms were performed and renal disease diagnosed. Case 23 was a 23-year-old with episodic diarrhoea, reflux oesophagitis and weight loss who had diabetes insipidus and was receiving growth hormone replacement. Case 24 was a hypertensive marathon runner taking captopril and

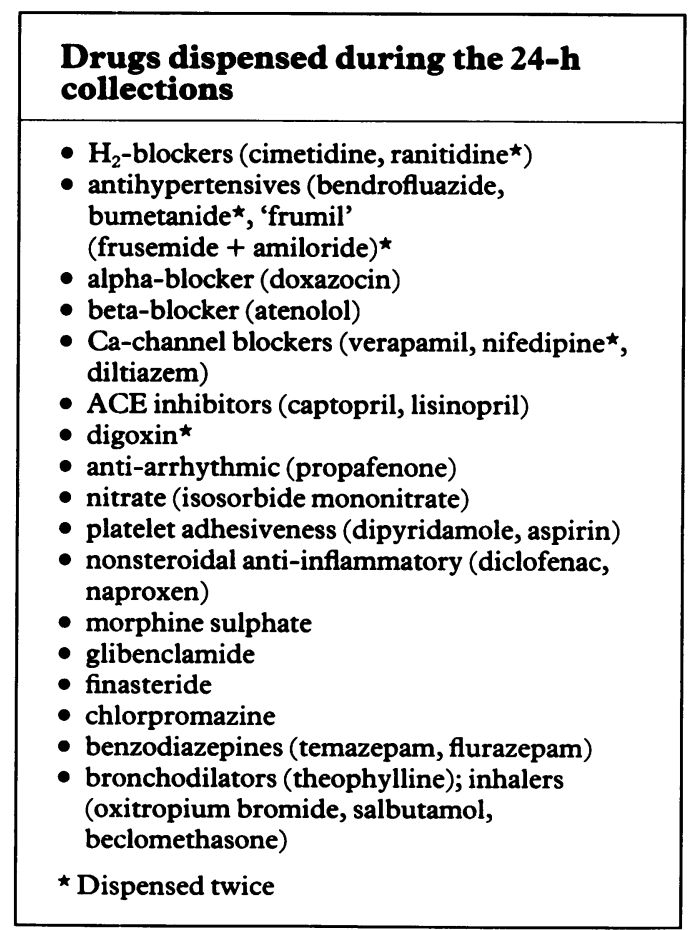

thiazides. It is apparent that no firm conclusion can be drawn in many of these cases as to whether the increased 5-HIAA is a coincidence or an indicator of disease. A complete listing of the drugs dispensed during the time period of the urine collections is given in box 1 .

\section{Discussion}

This study confirms the experience in Northern Ireland that the carcinoid syndrome is clinically rare. ${ }^{1}$ Flushing and diarrhoea are the usual symptoms associated with carcinoid tumour which precipitate a laboratory request for urinary 5-HIAA. Up to $5 \%$ of new onset flushing may be caused by the carcinoid syndrome and about $5 \%$ of patients with a carcinoid tumour develop symptoms of carcinoid syndrome. This depends on the site of the tumour with 30 to $60 \%$ of small bowel tumours, $1 \%$ of appendix and almost no rectal carcinoids causing symptoms. With gut carcinoids, the syndrome only develops when liver metastases occur and in one series $90 \%$ of tumours were not suspected ante mortem. ${ }^{6}$ Ninety per cent of patients with carcinoid syndrome complain of flushing. Flushing is not 5-HT mediated and substance $P$, neuropeptide $\mathrm{K}$, neurokinin A, bradykinin, prostaglandins and histamine are among the candidate mediators. ${ }^{2,7,8}$ Gastric carcinoids account for 3\% of gut carcinoids and the flush from these rare tumours is histamine mediated. ${ }^{9}$ Box 2 lists the common causes of flushing. A drug history is important to avoid unnecessary laboratory testing. Diarrhoea occurs in $75 \%$ of carcinoid syndromes and 5-HT inhibition reduces the episodes. Bronchospasm is also a feature in about $20 \%$. There is an association of neurofibromatosis, phaeochromocytoma and somatostatin-rich duodenal carcinoid syndrome. ${ }^{10}$ The potential symptom spectrum in carcinoid is wide.

About $75 \%$ of patients with carcinoid syndrome excrete more than $80 \mu \mathrm{mol}$ of 5-HIAA daily and a diagnostic specificity of $100 \%$ is claimed for this level if the dietary intake of fruits and drugs is controlled. ${ }^{2}$ Our findings do not confirm this assertion. Box 3 lists possible factors which may result in minor elevations of 5-HIAA excretion. ${ }^{11}$ Urinary 5-HIAA may be lowered in renal failure, by small bowel resec-

\begin{tabular}{l} 
Causes of flushing \\
\hline - menopause in women \\
- maeochromocytoma \\
- mastocytosis \\
- vipoma \\
- drugs: ethanol, antiandrogens, disulfiram, \\
chlorpropamide, diazoxide, hydralazine, \\
phentolamine, nitroglycerin, nicotinic acid, \\
dihydropyridine group (nifedipine, \\
nicardipine, amlodipine, felodipine, \\
isradipine) \\
\hline
\end{tabular}


tion and by aspirin, chlorpromazine and Ldopa. Benzodiazepines, naproxen, atenolol, chlorpromazine and possibly other agents were all potential confounding substances in our patients and drug-free specimens are the ideal. Analytical imprecision at low values near the reference value upper limit may have contributed to some of the slightly elevated values which were normal on repetition and the assay performance for higher values is well within the desired analytical goal of $<10 \%$ as a betweenbatch coefficient of variation. ${ }^{12}$ Inadvertent minor prolongation of the urinary collection period may have also been a contributory factor. Possible non-biological drug interferences are method dependent. Negative 5-HIAA results when carcinoid is strongly suspected may occur if 5-HTP or 5-HT are not being metabolised or if the 5-HIAA secretion is intermittent. ${ }^{13}$ In 5 -HT producing carcinoid tumours, urinary dopamine and HVA were increased in $18 \%$ and $27 \%$, respectively..$^{14}$ Our figures indicate that raised urinary HMMA and HVA values are not rare when 5-HIAA excretion is increased irrespective of the apparent underlying cause. 5-HT may be determined by HPLC in whole blood and in platelets but measurement of 5-HIAA simultaneously with HMMA and HVA is more convenient for this laboratory and the clinical demand for 5-HT has not arisen even though the published specificity for an increased urinary 5-HT in carcinoid tumour is $98 \% .{ }^{15}$ Ideally, the routine laboratory estimations of urinary 5-HIAA and 5-HT, and platelet 5-HT should be available for carcinoid tumour screening. CT and radionuclide MIBG, vasoactive intestinal peptide and octreotide scans, ultrasound and barium contrast studies may be used to try to

1 Watson RGP, Johnston CF, O'Hare MMT, et al. The frequency of gastrointestinal endocrine tumours in a welldefined population - Northern Ireland 1970-1985. QF Med 1989; 72: 647-57.

2 Kaplan LM. Endocrine tumors of the gastrointestinal tract and pancreas. In: Isselbacher KJ, Braunwald E, Wilson JD, Martin JB, Fauci AS, Kasper DL, eds. Harrison's principles of internal medicine. 13th edn. New York: McGraw Hill, 1994; pp 1535-42.

3 Anon. Octreotide. Lancet 1989; ii: 541-2.

4 Lightdale CJ. Tumors of small and large intestines. In: Stein $\mathrm{JH}$, ed. Internal medicine, 4th edn. St Louis: Mosby, 1994; pp 475-83.

5 Davidson DF. Simultaneous assay for urinary 4-hydroxy-3methoxy-mandelic acid, 5-hydroxyindoleacetic acid and homovanillic acid by isocratic HPLC with electrochemical homovanillic acid by isocratic HPLC with electroct

6 Berge T, Linell F. Carcinoid tumors: frequency in a defined population during a 12-year period. Acta Pathol Microbiol Scand 1976; 84: 322-30

7 Norheim I, Theordorsson-Norheim E, Broden E, Oberg K. Tachykinins in carcinoid tumors: their use as a tumor marker and possible role in the carcinoid flush. $f$ Clin Endocrinol Metab 1986; 63: 605-12. 8 Oates J. The carcinoid syndrome. N Engl F Med 1986; 315:
Causes of false positive raised urinary 5-HIAA levels

- coeliac disease

- bacterial gut overgrowth syndromes

- Whipple's disease

- foods: bananas, advocados, pineapples, walnuts, chocolate

- drugs: paracetamol, diazepam, oxprenolol, atenolol, phenothiazines, indomethacin, naproxen, reserpine, glyceryl guiaiacolate (found in some cough mixtures)

Box 3

\begin{tabular}{|l|}
\hline Summary/learning points \\
\hline - carcinoid tumours are rare - 1.3 per 100000 \\
half are in the appendix and are usually \\
symptom free \\
- carcinoid syndrome occurs in about 5\% of \\
carcinoid tumours \\
- with gut carcinoids, symptoms only occur \\
with liver metastases \\
- biochemical diagnosis is made by $24-\mathrm{h}$ urinary \\
5-HIAA and 5-HT and by platelet 5-HT \\
imaging using radiolabelled MIBG, \\
vasoactive intestinal peptide and octreotide \\
are especially useful for tumour localisation
\end{tabular}

Box 4

localise the tumour but often the primary lesion is small and difficult to find. There is no agreed threshold value of urinary 5-HIAA excretion that triggers the performance of a radionuclide scan, even though such imagery will detect up to $86 \%$ of carcinoid tumours. ${ }^{16}$

9 Roberts LJ II, Marney SR Jr, Oates JA. Blockade of the flush associated with metastatic gastric carcinoid by combined histamine $H_{1}$ and $H_{2}$ receptor antagonists: evidence for an important role of $\mathrm{H} 2$ receptors in human vasculature. $N$ Engl f Med 1979; 300: 236-8.

10 Griffiths DFR, Williams GT, Williams ED. Multiple endocrine neoplasia associated with von Recklinghausen's disease. BMY 1983; 287: 1341-3.

11 Salway J, ed. Drug-test interaction handbook, 1st edn London: Chapman and Hall Medical, 1990; pp 929-33.

12 Deacon AC. The measurement of 5-hydroxyindoleacetic acid in urine. Ann Clin Biochem 1994; 31: 215-32.

13 Whitley RJ, Meikle AW, Watts NB. Endocrinology Part IV, serotonin and 5-hydroxyindoleacetic acid. In: Burtis CA, Ashwood ER, eds. Tietz textbook of clinical chemistry, 2nd Ashwood ER, eds. Tietz textbook of clinical chemistry,
edn. Philadelphia: WB Saunders, 1994; pp 1765-75.

14 Feldman JM. Increased dopamine production in patients Feldman JM. Increased dopamine production in patie
with carcinoid tumours. Metabolism 1985; 34: 255-60.

15 Feldman JM. Urinary serotonin in the diagnosis of carcinoid tumours. Clin Chem 1986; 32: 840-4.

16 Hoefnagel CA. Metaiodobenzylguanadine and somatostatin in oncology: role in the management of neural crest tumours. Eur $\Im$ Nucl Med 1994; 21: 561-81. 